\title{
O ensaio no Ensino de Filosofia: um diálogo com Michel de Montaigne
}

The essay on Teaching Philosophy: a dialogue with Michel de Montaigne

\author{
DANIELLE ANTUNES ${ }^{1}$
}

\begin{abstract}
Resumo: A partir da interpretação da filosofia do ensaio proposta por Montaigne no Renascimento, enquanto um posicionamento ético e político do autor diante dos modos de produção dos conhecimentos e das subjetividades no âmbito cultural e pedagógico de seu tempo, acreditamos ser este posicionamento de grande alcance ainda hoje. Para tanto, procuramos problematizar a relação que se estabelece entre a filosofia e a educação popular no ensino superior brasileiro, propondo o exercício ensaístico como uma alternativa para as práticas do ensino de filosofia. Nossa interpretação visa uma abordagem do conceito de ensaio em Montaigne a partir de sua compreensão como um método performático de investigação, formação e criação. Tal procedimento proporciona aos estudantes uma experiência de ensino-aprendizagem através da escrita muito mais próxima e autêntica.

Palavras-chave: Montaigne. Filosofia. Ensaio. Ensino. Método.
\end{abstract}

Abstract: From the interpretation of the philosophy of the essay proposed by Montaigne in the Renaissance, as an ethical and political position of the author before the modes of production of knowledge and subjectivities in the cultural and pedagogical scope of his time, we believe that this position is still far reaching today. Therefore, we try to problematize the relationship established between philosophy and popular education in Brazilian higher education, proposing the essay exercise as an alternative to the practices of philosophy teaching. Our interpretation aims at approaching the concept of essay in Montaigne from its understanding as a performative method or procedure of research, training and creation, which provides students with a teaching-learning experience through much closer and authentic writing. Our interpretation aims at approaching the concept of essay in Montaigne from its understanding as a performatic method of investigation, training and creation. Such a procedure gives students a teaching-learning experience through much closer and authentic writing.

Keywords: Montaigne. Philosophy. Test. Teaching. Method.

Os Ensaios de Michel de Montaigne, escritos e publicados no século XVI na Renascença tardia na França, simbolizam muito mais do que a criação de um gênero textual ou a reinvenção do ceticismo no alvorecer da Modernidade; eles constituem o posicionamento ético e político do autor diante dos modos canônicos de produção

\footnotetext{
${ }^{1}$ Doutora em Filosofia pela Universidade Federal de Santa Catarina (2018), mestre em Educação na linha de pesquisa Filosofia da Educação (2012) e graduada em Filosofia (bacharelado e licenciatura) pela mesma instituição (2008). Atualmente sou professora adjunta na Universidade Estadual do Oeste do Paraná (UNIOESTE), campus Foz do Iguaçu e no Centro Universitário Dinâmica das Cataratas (UDC). Realizei estágio de doutorado (Programa de Doutorado Sanduíche no Exterior bolsista CAPES) na Universidade Jean Moulin - Lyon III, na França (2015). Atuei como coordenadora filosófico-pedagógica no Centro de Filosofia Educação para o Pensar, Florianópolis (2005-2008). Professora de Filosofia da rede estadual de ensino de SC, no Colégio Militar Feliciano Nunes Pires (2011 e 2012). Atuei também como tutora da disciplina História da Filosofia Moderna no curso de Filosofia da UFSC, modalidade EaD (2013.2). Coordenei o Grupo de Leitura dos Ensaios de Montaigne na UFSC (2016.1). E-mail: daniguassu@gmail.com.
} 
dos saberes e das subjetividades no âmbito cultural e pedagógico. A descoberta do indivíduo e da possibilidade da construção do Eu através da escrita, bem como a abertura que a escritura engendra no entendimento humano para a reorganização dos saberes sobre si mesmo, sobre o outro e sobre o mundo, configuram uma nova maneira de conceber a ciência, a filosofia e mesmo a educação. O que fica claro na leitura dos Ensaios é que os discursos da filosofia e das ciências não possuem nenhum valor intrínseco, e de nada valem se não servirem para tornar o sujeito que deles se apropria uma pessoa melhor e mais sensata. Toda ciência, toda filosofia e toda educação servem para formar o nosso ser, para aprimorar-nos, para que tenhamos não uma "cabeça bem cheia", mas uma "cabeça bem-feita" (I, 26, 224) ${ }^{2}$. Parafraseando Montaigne, o melhor espelho de todo e qualquer discurso (científico ou filosófico) é o curso de nossas vidas. Assim ele diz:

[A] Atentamos para as opiniões e o saber dos outros, e isso é tudo. É preciso fazê-los nossos. Parecemos exatamente alguém que, precisando de fogo, fosse pedi-lo em casa do vizinho e, encontrando um belo e grande, lá ficasse a se aquecer, sem mais de lembrar-se de levar um pouco para sua própria casa. De que nos servirá ter a pança cheia de comida, se ela não for digerida? Se não se transformar dentro de nós? Se não nos fizer crescer e fortalecer? (I, 25, 205).

É preciso trazer o fogo do conhecimento para a nossa própria casa, não para mobiliar a memória, mas para formar o juízo, para nos ensinar a pensar bem e a bem agir, pois, como diz Montaigne, "qualquer outra ciência é prejudicial para quem não tem a ciência da bondade" (Ibidem, 210). Assim, a dúvida cética presente no procedimento do ensaio se faz um antídoto contra a autoridade da tradição que, se repassada como um dogma inquestionável, não faz mais que tornar as "cabeças estúpidas" (Ibidem, 203). É por este motivo que Montaigne afirma:

[A] Trabalhamos apenas para encher a memória, e deixamos o entendimento $[\mathrm{C}]$ e a consciência $[\mathrm{A}]$ vazios. Assim como às vezes as aves vão em busca do grão e o trazem no bico sem o experimentar [tâter], para dar o bocado a seus filhotes, assim nossos pedagogos [pedantes] vão catando a ciência nos livros e mal a acomodam na beira dos lábios, para simplesmente vomitá-la e lançá-la ao vento. (Ibidem, 203).

A questão que se põe nos Ensaios, especialmente nos capítulos que abordam a problemática da educação - mas não apenas nestes -, é a respeito do modo como nos relacionamos com os saberes: pois se tratados como verdades definitivas incorremos nas armadilhas do dogmatismo, e, se utilizados apenas para tornar-nos mais eruditos e sabichões, revestem-nos de hipocrisia e falsidade. É precisamente sobre

\footnotetext{
${ }^{2}$ Adotamos como padrão para referência às citações dos Ensaios de Montaigne a disposição livro, capítulo, página da edição brasileira, nesta mesma ordem, como por exemplo: (I, 26, 243), onde "I" corresponde ao livro, "26" ao capítulo e "243" à página da edição brasileira.
} 
este aspecto da hipocrisia, relativa aos modos de produção e da apropriação dos saberes, e consequentemente dos modos de produção das subjetividades, que se situa boa parte da crítica de Montaigne aos homens de seu século e, consequentemente, a partir desta mesma crítica que ele irá propor o ensaio como um método filosófico de investigação e formação, no qual se dispõe a fazer filosofia em primeira pessoa, exercitando os seus julgamentos sobre todo e qualquer assunto, e construindo a sua própria subjetividade ao tomar a si mesmo como "objeto" de investigação e invenção.

O que é o ensaio afinal, e mais precisamente, o que é o ensaio montaigneano? Quando se fala dos Ensaios de Montaigne costumeiramente a primeira relação que se faz é com o gênero textual, e não por acaso. Montaigne foi de fato o inventor deste gênero e o primeiro escritor da história a intitular a sua obra de "Ensaios", inaugurando uma nova maneira de escrever que se estenderá por toda a Modernidade até os dias atuais.

Com efeito, o ensaio é, também, um gênero textual. Mas quando Montaigne intitula sua obra, ou quando diz que La Boétie escrevia "a maneira de ensaio" (I, 28), ou ainda quando afirma que se encontra em seus escritos "os ensaios de [suas] faculdades naturais" (II, 10), os ensaios de seus julgamentos (I, 50 e II, 17) e "um registro dos ensaios de [sua] vida" (III, 13), percebemos facilmente que se trata de um conceito muito mais amplo dentro da obra. E como afirma Hugo Friedrich, em Montaigne, "[...] ele [Montaigne] reserva de bom grado 'ensaio' (e 'ensaiar') para designar seu método intelectual, seu estilo de vida, sua experiência de si." (FRIEDRICH, 1968, p. 354), continuando mais adiante: “[...] Montaigne queria que seu título [Ensaios] fosse compreendido por referência à ideia de método significada por ensaio. Não era para ele uma etiqueta literária, como um poeta colocaria sobre seu livro “As poesias de...” (Ibidem, p. 355-356. Trad. nossa). Sendo assim, compreendemos o conceito de ensaio em Montaigne como o seu procedimento ou método filosófico de investigação, formação e criação, o qual se desdobra em uma dimensão experimental e performática. $O$ método do ensaio, que extravasa as fronteiras entre ciência e arte, entre a filosofia e a vida cotidiana, abre-nos a possibilidade da escrita autoral e intuitiva, permitindo que nosso pensamento e linguagem performe na folha em branco os traços e o estilo da pintura da nossa própria subjetividade.

\section{Sobre o ensaio como performance}

O conceito de ensaio, compreendido como um método que envolve um estilo de vida e a experiência de si, abarca em sua ação uma forma de viver que se estende à linguagem, formando com ela uma trama indissolúvel tal como marcas digitais: o ensaio é expressão e ação, é ato de fala transcrito, é o mostrar fazendo sem precisar esconder os "bastidores", ou, ensaiar escrevendo considerando o próprio processo 
como resultado. Desta maneira, podemos considerar o ensaio como uma performance de um sujeito que para tanto faz uso de tinta, papel e de suas experiências de vida; é uma miscelânea harmônica das múltiplas ideias, imagens e palavras expressadas por uma pessoa singular, compostas através do tempo em seu “registro de duração”, assim diz Montaigne:

[C] Não fiz meu livro mais do que meu livro me fez, livro consubstancial a seu autor, com uma ocupação própria, parte de minha vida; não com uma ocupação e finalidades terceiras e alheias, como todos os outros livros. Terei perdido meu tempo por prestarme contas de mim tão continuadamente, tão cuidadosamente? Os que se repassam apenas em pensamento e oralmente, de passagem, não se examinam tão essencialmente nem se penetram como quem faz disso seu estudo, sua obra e seu ofício, quem se propõe a um registro de duração, com todo seu ânimo, com toda sua força. (II, 18, 498).

O ensaio é uma performance: é um fluxo de pensamentos e sentimentos multiformes, que se dão na relação entre escritor e escrevência, manifestando em palavras o movimento da vida. É performático também porque se assemelha ao ato de esculpir, moldar, dar forma a algo; mas este algo é o si mesmo: a escrita assume papel de psicografia a fim de dar conhecimento de si para si: é uma escrita oracular $\Pi \alpha \eta \tau \alpha \rho \varepsilon \iota$ - porém profana, é o Eu que revela-se a si mesmo através de seus ensaios: como diz Auerbach, são "auto-ensaios" ou "ensaios consigo mesmo" (AUERBACH, 2004, p. 255). Sendo assim, o ensaio é uma investigação intuitiva, subjetiva e que se assume enquanto tal, permitindo que venha à tona do papel em branco até os pensamentos mais "indecisos e, se calhar, opostos", pois, como se justifica Montaigne: "ou porque eu seja um outro eu, ou porque capte os objetos por outras circunstâncias e considerações" (III, 2, 27-28); é o fluxo da subjetividade expressado e registrado em palavras, algo parecido com o que mais tarde veio se caracterizar em psicologia e psicanálise como terapia através da fala e a livre associação de ideias, e na área da criação como brainstorming.

O ensaio é principalmente performático porque, apesar de ser comportamento restaurado, ele nunca acontece da mesma maneira, seja porque as circunstâncias sejam outras, seja porque o performer é um outro não apenas a cada sete anos ou a cada dia, mas é outro a cada minuto, a cada piscar de olhos, como tão bem o definiu seu inventor, Michel de Montaigne. O ensaio é obliquamente de filiação heraclitiana e seu lema também é $\Pi \alpha \eta \tau \alpha \rho \varepsilon \iota$ - o pensamento, a escrita, a vida, o humano, a natureza - tudo flui.

O ensaio, como queremos caracterizar, é fruto da nossa condição humana filosofante e comunicativa, sempre considerando a nossa falibilidade; é também fruto da nossa curiosidade e inquietação, da vontade intermitente de investigar e desvendar o mundo, fazendo uso da linguagem e do método experimental de 
tentativa e erro. Muito próximo à poesia, às cartas, aos diálogos, autobiografias, diários e confissões, embora cada um tenha a sua peculiaridade; o ensaio não está tão comprometido com o verso e a imagem como na poesia, nem com um remetente como nas cartas, tampouco em atribuir suas intuições e variações de perspectivas à personagens à moda dos diálogos; e, apesar de ser uma escrita de si, não está preso à cronologia como as autobiografias e os diários; sua intenção não é um relato diário de experiências da vida do escritor ou declarações confessadas em um momento de reflexão com uma finalidade ascética: ele se assemelha mais a um passeio descomprometido e sem um rumo pré-determinado, ao acaso de um pensamento genuinamente filosófico sobre a vida ordinária e, como tal, cotidianamente escrito. A sua arquitetura é poética: o que a guia não é a estrutura lógica ou sistemática na apresentação de um problema ou argumento, mas a vontade, as paixões, fantasias e imaginações apresentadas de forma harmônica (dentro de sua natureza caótica): é a livre associação de ideias, impressões e intuições, e não a lógica, o que lhe dá forma, "a primeira frase produz a segunda" (I, 40, 377). Contudo, isto não implica um irracionalismo, mas uma outra poética da criação e construção filosófica. Um outro paradigma de racionalidade, voltado especialmente à comunicabilidade humana ao tentar expressar sua condição mutante, falível e finita, antes que à capacidade lógica, geométrica ou matemática do entendimento humano.

Deixando entrelaçar-se em seu tecido fantasias, paixões e vontades, o ensaio permite que a humana condição ganhe forma e face, e que possa construir assim uma pintura mais fiel a si - seja lá o que for o si mesmo, e ainda que nunca idêntico. Encarar-se e pintar-se em suas contradições e em seus processos pode não formar o quadro mais belo e perfeito, mas certamente este será mais franco e honesto: e eis o seu comprometimento com a verdade. A partir da perspectiva do ensaio, o princípio lógico da não-contradição deixa de ser um princípio para a organização das ideias: é preciso aceitar as contradições de si para se colocar em estado ensaiador.

É importante ressaltar a temporalidade, ou a experiência temporal (embora não cronológica) do ensaio, sem previsão esquemática, o ensaio é registro do fluxo do tempo na imprevisibilidade da vida, o tal "registro de duração" denominado por Montaigne. Contrário à tentativa de fundamentação de uma explicação, é no registro da passagem, do transitório, do cambiante e do imprevisto que ele se desdobra, atua, se inscreve: "Eu não pinto o ser, eu pinto a passagem [...]". Leiamos Montaigne:

[B] Os outros formam o homem; eu o narro [récite], e represento um em particular, bem malformado, e o qual, se tivesse de moldar novamente, eu faria verdadeiramente outro bem diferente do que é. Mas agora está feito. Ora, os traços da minha pintura não se extraviam, embora mudem e diversifiquem-se. O mundo não é mais que um perene balanço [branloire pérenne]. Nele todas as coisas se 
movimentam sem cessar: a terra, os rochedos do Cáucaso, as pirâmides do Egito, e tanto com o movimento geral como com o seu particular. A própria constância não é outra coisa senão um movimento mais lânguido. Não posso assegurar meu objeto. Ele vai confuso e cambaleante, com uma embriaguez natural. Pego-o neste ponto, como ele é, no instante em que me entretenho com ele. Eu não pinto o ser. Eu pinto a passagem: não a passagem de uma idade à outra, ou como diz o povo, de sete em sete anos: mas de dia a dia, de minuto a minuto. É preciso acomodar minha história à hora. Eu poderei tanto mudar, não de fortuna somente, mas também de intenção: Este é um registro de diversos e mutáveis acontecimentos, e de imaginações irresolutas. E quando for o caso, contrárias: Seja que sou outro eu mesmo: Seja que apreenda os assuntos, por outras circunstâncias e considerações. Seja como for, pode ser que eu me contradiga, mas a verdade, como dizia Demades, não a contradigo não. Se minha alma pudesse prender pé, eu não me ensaiaria, eu me resolveria: Ela está sempre em aprendizagem e em prova. (III, 2, 2728).

Pintar a passagem daquilo que está em movimento constante, à maneira de ensaio, é tentar narrar aquilo que não pode ser previsto nem fixado, aquilo que é efêmero e imprevisível e, por isso, deve ser adaptado ao momento presente. $\mathrm{O}$ ensaísta não forma o homem - "Os outros formam o homem[...]" -: ele performa a si mesmo. Ele percorre, com seu pincel, com sua pena e com seu corpo - "à saltos e cambalhotas" (III, 9, 315) - o mutável e o inapreensível. Aos fragmentos, camadas e pinceladas, e a cada piscar de olhos, ele pinta seu quadro interminável, ciente da sua irresolução, mas principalmente, consciente de que tudo é aprendizagem. De que sua escrita e seus atos são meramente ensaios, e não contratos, como tão bem notou Nietzsche em seu Assim falou Zaratustra:

Quem pode mandar, quem deve obedecer - isso ali se ensaia! Ah, com tantas buscas, conjecturas, fracassos, aprendizados e novos ensaios!

A sociedade humana: é um ensaio, como eu ensino - uma longa busca: mas ela busca aquele que manda! -

Um ensaio, ó meus irmãos! E não um "contrato"!

Destroçai, destroçai essa palavra dos corações débeis, e meio-isso, meio-aquilo! (NIETZSCHE, 2011, p. 2013).

Relatar as buscas, as conjecturas, os fracassos (!), enfim, os aprendizados: relatar sempre novos ensaios! Infinitos ensaios, pois as novas configurações processuais a cada piscadela, pedem novos ensaios. E quem quiser esmiuçar engenhosamente as prenhes sugestões que eles trazem, este "produzirá infinitos ensaios" (I, 40, 374).

\section{O ensaio no ensino de filosofia}


A relação entre teoria e prática na educação filosófica proposta por Montaigne pode ser compreendida a partir de um conceito-metáfora: a estamina, que pode ser traduzida como o crivo do juízo. Tal metáfora faz alusão ao processo de peneiragem ou de filtragem que o entendimento humano é capaz de operar ao se deparar com qualquer opinião que a ele se apresente sobre qualquer assunto. Esta peneiragem consiste no uso do senso crítico do julgamento, o qual opera uma análise dos argumentos em tal questão, deliberando sobre seu assentimento ou não. Justamente o que se coloca é a liberdade de escolha do sujeito diante de qualquer que seja a posição ou argumento que lhe é apresentado, independentemente da força da autoridade. Para o sujeito que faz uso da sua liberdade judicatória há sempre três opções de escolha: concordar, não concordar ou permanecer em dúvida. O exercício dessa faculdade do juízo, de modo livre e autônomo, é o que confere ao sujeito a formação do seu entendimento. Poder escolher como um exercício de liberdade, a partir da sua própria subjetividade, é o caminho que proporcionará ao indivíduo a formação da "cabeça bem feita". Assim, unir os exemplos da filosofia moral às nossas próprias ações e deliberações, procurando moldá-las à nossa vida singular, é o que em Montaigne se pode designar como a pedagogia filosófica do ensaio, pois a filosofia para Montaigne possui sempre um carácter formativo e propedêutico.

A filosofia dos Ensaios se caracteriza pelo uso que dela podemos fazer, pela aplicação à nossa própria vida e experiência de si, pois a teoria por si mesma não possui nenhum valor se não puder ser incorporada e assimilada, se não puder contribuir para nossa formação intelectual e moral e nos tornar pessoas melhores.

Vemos com esta postura crítica de Montaigne a suspensão de um assentimento imediato face aos conhecimentos livrescos advindos da tradição. É preciso barrar o curso das ideias caso a elas não assentirmos, ainda que sejam ideias de Aristóteles, Cícero ou Platão. Porém, se com eles concordarmos, não serão mais ideias alheias, mas sim as nossas, pois sua validade só se comprova com a sua assimilação e incorporação em nossas vidas e ações. Ele diz: "Não é segundo Platão mais do que segundo eu mesmo, já que ele e eu o entendemos e vemos da mesma forma" (I, 26, 227). Assim, Montaigne alega que a filosofia não é máscara nem uma cauda de filósofo que o sujeito cola à si mesmo ou que o preceptor cole a seu aluno, mas é alimento para a alma e para o corpo, alimento que se torna sangue vivo circulando em nossas veias. Assim, no capítulo Da educação das crianças, ao sugerir como um preceptor deve conduzir seu aluno, ele diz:

[A] Que ele [o preceptor] o faça passar tudo pelo crivo [l'étamine] e nada aloje em sua [do aluno] cabeça por simples autoridade e confiança; que os princípios de Aristóteles não lhe sejam princípios, não mais que os dos estóicos e epicuristas. Que lhe proponham essa diversidade de opiniões; ele escolherá se puder; se não, permanecerá em dúvida. [C] Seguros e convictos há apenas os loucos" (I, 26, 226). 
A filosofia é tratada por Montaigne como formadora de nossos costumes e de nós mesmos e se trata de uma conversão, de uma modificação no modo de viver, de ver e pensar, a qual o sujeito que dela faz uso pode alcançar. E a maneira que o autor a põe em prática é através de seus ensaios, mostrando-nos que é possível partir do não filosófico rumo ao filosófico, pelas vias de um método discursivo, experimental e performático, que nos coloca em posição de autores com nossa linguagem cotidiana, capazes de investigar, de buscar a nossa formação e de darmos forma a nós mesmos.

\section{Referências}

ANTUNES, D. "Par manière d'essai". Montaigne e a Filosofia do Ensaio. Florianópolis: Universidade Federal de Santa Catarina, 2018 [Tese de Doutorado].

AUERBACH, E. L'humaine condition. In: Mimesis: a representação da realidade na literatura ocidental. Vol. 2. São Paulo: Perspectiva, 1971, p. 247-276.

FRIEDRICH, H. Montaigne. Trad. Robert Rovini. Paris: Gallimard, 1968.

MONTAIGNE, M. Os Ensaios. Livro III. Trad. Rosemary Costhek Abílio. São Paulo: Martins Fontes, 2001.

Os Ensaios. livro I. 2. ed. Trad. Rosemary Costhek Abílio, precedido de "um estudo sobre Montaigne”, de Pierre Villey sob direção e com prefácio de V.-L. Saulnier. São Paulo: Martins Fontes, 2002.

. Os Ensaios. Livro II. 2. ed. Trad. Rosemary Costhek Abílio. São Paulo: Martins Fontes, 2006.

NIETZSCHE, F. Assim falou Zaratustra: um livro para todos e para ninguém. Trad. notas e posfácio Paulo César de Souza. São Paulo: Companhia das Letras, 2011.

Submissão: 20.10.2018 / Aceite: 30.11.2018. 